\title{
Mycorrhizal synthesis between Pisolithus arhizus and adult clones of Arbutus unedo in vitro and in nursery
}

\author{
Filomena Gomes • Helena Machado • Esteban San Martin \\ A. Portugal • Jorge M. Canhoto
}

Received: 2012-03-16; $\quad$ Accepted: 2012-06-28

(C) Northeast Forestry University and Springer-Verlag Berlin Heidelberg 2013

\begin{abstract}
Arbutoid mycorrhizae were synthesized between adult selected clones of Arbutus unedo L. and Pisolithus arhizus. Two micropropagated clones were tested: AL1, in vitro and $\mathrm{C} 1$ (acclimatized plants) in nursery and later in a field trial. In vitro, rooted shoots were transferred to test tubes containing the substrate previously inoculated with mycelium cultured on agar. In the nursery, two inoculation treatments were tested (vegetative inocula or dry sporocarps) and compared to control plants. In the field trial, plants from nursery inoculation treatments were compared and an additional control treatment using seedlings was implemented. Plant height was evaluated 4 months later in the nursery and 20 months later in the field trial. Roots were examined by morphological and histological studies: a) in vitro plantlets one month after inoculation and nine months after acclimatization; and b) 20 months after the field trial was established. Arbutoid mycorrhizae were observed in vitro one month after inoculation, indicating compatibility between $A$. unedo and $P$. arhizus. These showed the presence of a mantle, Hartig net, and intracellular hyphal complexes confined to the epidermal root cells. Arbutoid mycorrhizae were also observed nine months after acclimatiza-
\end{abstract}

Fund project: This work was supported by a $\mathrm{PhD}$ fellowship (SFRH/BD/37170/2007) from the Portuguese Foundation for Science and Technology (FCT)

The online version is available at http://link.springer.com

Filomena Gomes ( Esteban San Martin

Filomena Gomes. CERNAS, Dep. Recursos Florestais, Escola Superior Agrária Coimbra, Bencanta, 3040-316, Coimbra, Portugal, Tel: 351239 802940, Fax: 351239 802979, Email: fgomes@esac.pt

Helena Machado

INIAV, Instituto Nacional de Investigação Agrária e Veterinária, IP., Av. República, Quinta do Marquês 2780-159 Oeiras, Portugal

A. Portugal • Jorge M. Canhoto

Centre of Functional Ecology, Department of Life Sciences, University of Coimbra, Ap. 3046, 3001-401 Coimbra, Portugal.

Corresponding editor: Chai Ruihai tion in inoculated and control plants. In order to confirm the identity of mycorrhizae, molecular techniques were used, in previously inoculated in vitro plants, 12 months after acclimatization. Thelephora and Hebeloma mycorrhizae, two types of highly competitive and widespread mycorrhizae on nurseries were identified. In the nursery, dry sporocarp treatment improved plant height after four months. In a field trial (20 months later), plants growth did not show significant differences. By this time, mycorrhized roots with Cenococcum geophilum and other types were identified. These results and their implications on $A$. unedo breeding program are discussed.

Keywords: arbutoid mycorrhizae; Ericaceae; field plants; Arbutus unedo or strawberry tree

\section{Introduction}

Arbutus unedo (known as strawberry tree) grows spontaneously in Mediterranean ecosystems. Fruit production represents the main income for farmers. From an ecological perspective, it contributes to biodiversity, helps to stabilize soils, has a strong regeneration capacity following fires, and survives well in harsh environments (Piotto et al. 2001). Because of these characteristics, it has been used in the colonization of marginal lands and to prevent the propagation of forestry fires. For the last five years, we have been involved in a long-term breeding program, in which the main goal is to select and propagate trees to improve the quality of plant material available for orchards, hence enhancing the potential of $A$. unedo as a crop. In close collaboration with farmers, trees have been selected based on fruit production and quality, and protocols for the propagation of these adult trees through axillary shoot proliferation (Gomes and Canhoto 2009; Gomes et al. 2010) and somatic embryogenesis (Gomes et al. 2009; Lopes et al. 2011) were developed.

Mycorrhizae can improve plant adaptation and tolerance to stressful environmental conditions. Species of Arbutus (Ericaceae) form mycorrhizae with a broad range of fungal partners (Massicotte et al. 1993). Ultrastructural studies classified as ar- 
butoid mycorrhizae those formed by Arbutus, Arctostaphylos and Pyrola plants (Smith and Read 1997). Structurally, this kind of mycorrhizae resembles the ectendomycorrhizae since they possess a mantle, Hartig net and form intracellular hyphal complexes. However, they differ from ectendomycorrhizae by the fact that the intracellular hyphal complexes are restricted to the epidermal cells (Peterson and Massicotte 2004). Massicotte et al. (1993) added to the characteristics of arbutoid mycorrhizae the presence of a variable fungal sheath.

Previous works have shown that fungi involved in the formation of arbutoid mycorrhizae are also able to form ectomycorrhizae in association with other plant hosts as is the case of the basidiomycete Pisolithus arhizus, a symbiont fungus for a broad plant host range (Massicotte et al. 1993; Molina and Trappe 1982). Earlier studies had already shown the lack of specificity in hosts forming arbutoid mycorrhizae (Molina and Trappe 1982). Accordingly, other experiments indicated that Arbutus menziesii and Arctostaphylos uva-ursi were able to develop arbutoid mycorrhizae in association with fungi that also can form ectomycorrhizae, including Cenococcum geophilum, Hebeloma crustuliniforme, Laccaria laccata, Lactarius sanguifluus, Piloderma bicolor, Pisolithus arhizus, Poria terrestris var. subluteus, Rhizopogon vinicolor and Thelephora terrestris (Molina and Trappe 1982; Smith and Read 1997). From these studies, it became clear that the plant host plays a crucial role in regulating the development and structure of mycorrhizae and that the same type of fungi may originate different types of mycorrhizae according to the plant species that was colonized (Mirabelli et al. 2009; Rai 2001).

Studies performed by Richard et al. (2005) also point in this direction because they have indicated that two mycorrhizal hosts, A. unedo and Quercus ilex growing in an old Mediterrean forest dominated by Quercus ilex, tend to share a few ectomycorrhizal species $(<15 \%$ of the ectomycorrhizal diversity). The molecular analysis performed by these authors enabled the identification of 28 taxa ( $81 \%$ of the characterized mycorrhizae), with the family Thelephoraceae being the most represented (Richard et al. 2005). Interactions between fungal strain and plant species in other Ericaceae such as Rhododendron sp. and Vaccinium corymbosum also showed that the type of fungal strain used affects mycorrhization and further plant growth (Eccher and Martinelli 2010; Noé et al. 2002). Taken together, all these data indicate that the selection of the most effective fungal strains under nursery and field conditions is a prerequisite for the successful establishment of mycorrhizae (Parladé et al. 2004; Rai 2001).

Mycorrhizal fungi use a variety of nitrogen sources and enhance mineral uptake (Gobert and Plassard 2008). This capacity is particularly advantageous for woody plants, conferring upon them a selective advantage in natural conditions since not only water and mineral (e.g., nitrogen and phosphorous) uptake is increased but root growth is buffered against biotic and abiotic stresses (Harrison 1999; Smith and Read 1997). In orchards, mycorrhization is no less important since plant growth can be stimulated and, therefore, crop production (Gobert and Plassard 2008). In this way, mycorrhizal synthesis experiments are useful to determine fungus-plant host compatibility (Águeda et al.
2008). This study is a first attempt to induce mycorrhizae formation between Arbutus unedo and P. arhizus (Pisolithaceae) under in vitro conditions, a type of symbiosis that does not seem to occur in natural stands (Richard et al. 2005). The role of mycorrhization on plant growth and survival was evaluated in the nursery and in a field trial. Morphological and histological analyses were carried out to monitor mycorrhizae synthesis.

\section{Materials and methods}

Fungal isolation and growth

Fungal isolate of $P$. arhizus was obtained from a sporocarp collected in the centre of Portugal, in a Mediterranean old-growth Quercus suber forest stand (Vendas Novas: $38^{\circ} 41^{\prime} \mathrm{N}, 8^{\circ} 29^{\prime} \mathrm{W}$ ). Isolation was carried out by culturing sporocarp on modified Melin Norkrans (MMN) agar culture medium (Jacob et al. 2001). Fungal cultures were cultivated at $30^{\circ} \mathrm{C}$ and multiplied by transferring five small discs of vigorously growing mycelium to fresh media containing $2 \%(\mathrm{w} / \mathrm{v})$ glucose every four weeks. The same culture in liquid medium, in which glucose was reduced to $1 \%$ $(\mathrm{w} / \mathrm{v})$, was used for mycelium growth and, afterwards, for vegetative inoculum of the substrate in nursery conditions. P. arhizus dry sporocarps were also tested in nursery conditions. In this case, the dry sporocarps were collected in Carregal-do-Sal $\left(40^{\circ} 26^{\prime} \mathrm{N}, 7^{\circ} 59^{\prime} \mathrm{W}\right)$, in an old Eucalyptus globulus forest stand.

\section{Plant material}

Adult trees of $A$. unedo were selected based on fruit quality and production (AL1 and $\mathrm{C} 1$ clones). The conditions for plant establishment were described in a previous work (Gomes and Canhoto 2009). Briefly, branches (30-40 cm length) of adult plants were collected in the field, disinfected and kept in a culture chamber covered with plastic bags to maintain a high humidity environment, thus stimulating the development of epicormic shoots. Shoot apices and nodal segments from these epicormic shoots were further used to establish in vitro cultures on an Anderson medium (Anderson 1984). Propagation of the established material was accomplished on De Fossard medium (De Fossard et al. 1974). The higher shoots (14-20 mm) were transferred to a rootinduction medium (Knop, Gautheret 1959) added of $24.6 \mu \mathrm{M}$ IBA (indol 3-butyric acid), for one week, in dark conditions. Shoots were then transferred to the same medium (Knop), without auxin and containing charcoal $(1.5 \% \mathrm{w} / \mathrm{v}$; root development medium) and sucrose $(3 \% \mathrm{w} / \mathrm{v})$ for another four weeks, before being acclimatized in the greenhouse.

Shoots from AL1 clone were tested under in vitro conditions. After root induction, shoots were transferred to the root development medium for two weeks before being transferred to the inoculated substrate. Rooted shoots were then transferred to the substrate inoculated with $P$. arhizus or to the control (the substrate not inoculated). In both cases, 45 plantlets were tested.

Inoculation in nursery conditions with $P$. arhizus was performed using micropropagated plants from a selected clone 
named $\mathrm{C} 1$. After acclimatization in the greenhouse, $\mathrm{C} 1$ plants were transferred to pots $\left(450 \mathrm{~cm}^{3}\right)$ for plant development and, afterwards, transferred to the nursery before the mycorrhizal inoculation treatments. A mixture of peat and perlite $(7: 3 ; \mathrm{v} / \mathrm{v})$ was used as substrate. Two inoculation treatments (vegetative inocula from the same strain tested in vitro or dry sporocarps) were tested and compared to control plants. Those plants were later installed in a field trial and both $P$. arhizus treatments were compared to the control (micropropagated plants) as well as to one-year-old seedlings produced in the nursery.

\section{Mycorrhizal synthesis}

To induce mycorrhizal synthesis, test tubes $(3 \mathrm{~cm}$ in diameter and $30 \mathrm{~cm}$ height), containing a $40 \mathrm{ml}$ mixture of peat and vermiculite $\left(1: 6.5 \mathrm{v} / \mathrm{v}\right.$; previously sterilized at $121^{\circ} \mathrm{C}$ for $\left.60 \mathrm{~min}\right)$ were used. The pure culture synthesis technique described by Molina (1979) was used as a basis. The modifications were as follows: 1) the MMN liquid medium, with a low glucose concentration $(0.5 \% \mathrm{w} / \mathrm{v})$, was added in a proportion of $30 \%$ (substrate/volume); 2) for inoculation, three small discs ( $1 \mathrm{~cm}$ diameter) of vigorously growing mycelium cultured on Petri dishes were added per tube; 3) tubes were incubated at $30^{\circ} \mathrm{C}$ for one month followed by 15 days in a culture chamber $\left(25 / 20^{\circ} \mathrm{C}\right.$, in the dark), to allow mycelium development. Finally, induced rooted shoots of the AL1 clone were transferred to the synthesis tubes. Control shoots were transferred to tubes containing noninoculated substrate, but in which liquid medium (Knop), charcoal $(1.5 \%)$ and sucrose $(3 \%)$ were added. The synthesis tubes with AL1 shoots were maintained in a culture chamber under a photoperiod of $16 / 8 \mathrm{~h}$ and a temperature of $25 / 20^{\circ} \mathrm{C}$, respectively. The substrate and mycelium were kept dark by wrapping the basal part of the tubes with aluminium foil. A small amount (3 to $5 \mathrm{ml}$ per tube) of liquid medium, consisting on Knop macronutrients, was added monthly during five months. After 1 month, 8 plants were checked for mycorrhizal formation.

After five months, all plantlets were acclimatized as described by Gomes and Canhoto (2009). Briefly, the containers (60 x 40 $\mathrm{cm})$ were covered with plastic and placed on an irrigation sheet in a greenhouse to maintain a moist environment. The degree of humidity was gradually reduced by raising the covertures after three to four weeks, which were then totally removed after six weeks. During acclimatization, plantlets were evaluated for the presence of mycelium, mycorrhizae and root development. Half a month, later plants were transferred to individual containers, containing the substrate described above, and later the plants were transferred to the nursery. Four months later, the survival rate was determined.

Nine months after acclimatization, roots from both treatments (control and previously inoculated in vitro) were again examined for arbutoid mycorrhizae formation. Twelve months after acclimatization, 10 plants in the nursery (from previously in vitro inoculated treatment) were removed from containers and the identity of distinct mycorrhizal types were analyzed by molecular techniques. Young roots were frozen in liquid nitrogen and stored $\left(-80^{\circ} \mathrm{C}\right)$. Samples were homogenized and DNA extrac- tions were performed using the automatic extractor ABIPRISM 6100 Nucleic Acid Prepstation from Applied Biosystems, according to manufacturer instructions. ITS1F and ITS4 primers were used to amplify the ITS (Internal Transcribed Spacer) total region (Gardes and Bruns 1993; White et al. 1990). PCR was performed in a $25 \mu 1$ volume containing: $12.5 \mu$ l of Jump Start Taq DNA polymerase with $\mathrm{MgCl}_{2}$ (Sigma D 9307), $0.5 \mu \mathrm{l}$ of each primer $(10 \mathrm{mM}), 1 \mu \mathrm{l}$ of template DNA and $10.5 \mu 1$ of sterile distilled water.

The initial denaturation step $\left(2 \mathrm{~min}, 95^{\circ} \mathrm{C}\right)$ was followed by 30 cycles of $60 \mathrm{~s}$ at $95^{\circ} \mathrm{C}$ (denaturation), $60 \mathrm{~s}$ at $53^{\circ} \mathrm{C}$ (annealing) and an extension step of $60 \mathrm{~s}$ at $72^{\circ} \mathrm{C}$, followed by a final extension step at $72^{\circ} \mathrm{C}$ for 5 minutes, to guarantee that all annealed templates were entirely polymerized. The amplification reactions were performed with a GeneAmp PCR 9700 thermocycler from Applied Biosystems. PCR products were then purified using the QIAquick PCR Purification Kit (Qiagen Inc., Chatsworth, USA) and directly sequenced on an ABI 3730 genetic analyzer, using the Big Dye v.3 Terminator Cycle Sequencing Ready Reaction Kit (Applied Biosystems). The nucleotide sequences were run through Geneious 6.1 (cross-platform bioinformatics software suite for exploring biological data such as DNA sequences) and compared to the Blast (Basic Length Alignment Search Toll) (Altschul et al. 1997) database from NCBI (http://blast.ncbi.nlm.nih.gov/Blast.cgi). Sequence identification is then presented according to the degree of genetic similarity between the nucleotide sequence and the closest match in GeneBank.

Mycorrhization in the nursery and field tests

To analyse mycorrhization with $P$. arhizus in the nursery, clonal micropropagated plants $(\mathrm{C} 1)$ were watered with either $P$. arhizus mycelium (pure cultures in MMN liquid medium) or dry sporocarps and compared with the control. Pure cultures were obtained in $\mathrm{MMN}$ liquid medium (glucose $1 \% \mathrm{w} / \mathrm{v}$ ) at $30^{\circ} \mathrm{C}$ for two months. When the liquid surface was covered with the mycelium, the Erlenmeyer flasks were gently shaken, filtered, and washed to remove the remains of glucose. The mycelium was diluted in water in a proportion of 1:20 (v/v), and then applied to the substrate (treatment referred to as $\mathrm{C} 1 \mathrm{M}$ ). The dry sporocarps were mixed with water and then applied directly to the substrate (treatment referred to as $\mathrm{C} 1 \mathrm{~S}$ ). In both treatments, $80 \mathrm{ml}$ were applied (during the growing season spring) to the substrate (450 $\mathrm{cm}^{3}$ ) being distributed by three holes previously made in the direction of the plant roots. The fertilizer addition (slow-release fertilizer, 20:9:11 NPK $+2 \mathrm{Mg})$ to the substrate $(2.6 \mathrm{~g} / \mathrm{l})$ was only applied to the control treatment (treatment referred to as $\mathrm{C1C}$ ). A total of 153 plants distributed by the different treatments were used: 45 for C1S, 49 for $\mathrm{C} 1 \mathrm{M}$ and 59 for C1C. The effect of the treatments on plant growth was evaluated by measuring the increase in plant height $\left(\mathrm{H}_{1}-\mathrm{H}_{0} ; \mathrm{cm}\right)$, two and four months after inoculation treatments in nursery.

Four months after inoculation treatments in the nursery these plants were installed in the field trial and compared to one-yearold strawberry tree seedlings propagated in the nursery, an ap- 
proach commonly used in afforestation programs. The field trial was established in Estreito ( $39^{\circ} 57^{\prime} \mathrm{N}, 7^{\circ} 48^{\prime} \mathrm{W}$ ) during the most adequate planting season for a Mediterranean climate (October). Plants from all the mycorrhization treatments (C1S, C1M, C1C) were kept in the field without the addition of any fertilizer and compared in terms of growth with seedlings treated with a slowrelease fertilizer (30g/plant; Nutriforest 9:23:14 $(+4 ;+0.1) \mathrm{N}: \mathrm{P}: \mathrm{K}$, $+\mathrm{MgO}, \mathrm{B}$, with eight to nine months of release period). This is the usual procedure used in afforestation programs, considering the climatic and edaphic characteristics of the Region. However, plants from all the mycorrhization treatments, including the control were not fertilized. Plants were established in rows at a distance of $4 \mathrm{~m}$ apart and $5 \mathrm{~m}$ between rows $(4 \mathrm{~m} \times 5 \mathrm{~m})$. The experiment consisted of four blocks with five plants per each of the four treatments in a total of 80 plants (four treatments $\mathrm{x}$ five plants $\times$ four blocks) distributed in an area of $1600 \mathrm{~m}^{2}$. Survival rate was evaluated 12 months after tree planting. Height was measured immediately after planting and then 20 months later to evaluate the effect of the different treatments tested on plant growth. By this time, roots were also checked for the presence of arbutoid mycorrhizae.

\section{Morphological and histological studies}

Arbutoid mycorrhizae roots and rhizomorphs were carefully examined with the aid of a stereo-microscope. Some observations were carried out in fresh sections obtained with a freezing microtome. The general terminology follows that of Agerer and Rambold (2004-2010).

For histological studies, root samples were fixed in $2.5 \%$ glutaraldehyde in a $0.1 \mathrm{M}$ phosphate buffer, $\mathrm{pH} 7.0$ for $1.5 \mathrm{~h}$ and post-fixed in $1 \%$ osmium tetroxide prepared in the same buffer for $1 \mathrm{~h}$ at room temperature. Dehydration was accomplished in an ethanol series (20\% to $100 \%)$ and the samples were embedded in Spurr's resin. Sections ( $1-2 \mu \mathrm{m})$ were made with glass knives on a LKB Ultratome III and stained with $0.2 \%$ toluidine blue.

\section{Statistical analysis}

For statistical analysis, the software STATISTICA 6 was used. An ANOVA was performed to check the effect of the different inoculation treatments with $P$. arhizus on plant height and height increment $(\Delta \mathrm{H})$ under nursery conditions. Following establishment of the field trial, an ANOVA was performed considering the two main factors (the inoculation treatments and block/field trial repetition) and their interaction on two variables: plant height and height increment 20 months after field trial establishment. When treatments showed significant differences $(p \leq 0.05)$, means were compared using the Duncan test (Duncan 1955).

\section{Results}

\section{Mycorrhizal synthesis in vitro}

Five months after the beginning of the experiments, all in vitro plantlets were acclimatized (Figs. 1a-e). The root system showed many secondary and branched roots (Fig. 1c-d) which likely contributed to the $100 \%$ survival rate evaluated four months later. Plants that were not inoculated showed a slightly lower survival rate of $93.8 \%$ (four months after acclimatization), without significant differences. After five months on the synthesis tubes, the main features that could be observed were: 1) a well-developed root system showing the presence of secondary roots (Fig. 1c), 2) an extensive colonization of the substrate by the mycelium of $P$. arhizus (Figs. 1d-e), 3) with a thick yellow-brown mantle visible to the naked eye, and completely covering the roots (Figs. 1c-e), and 4) a normal pattern of plant development indicating that colonization of the roots by $P$. arhizus does not affect plant growth (Figs. 1c-d).

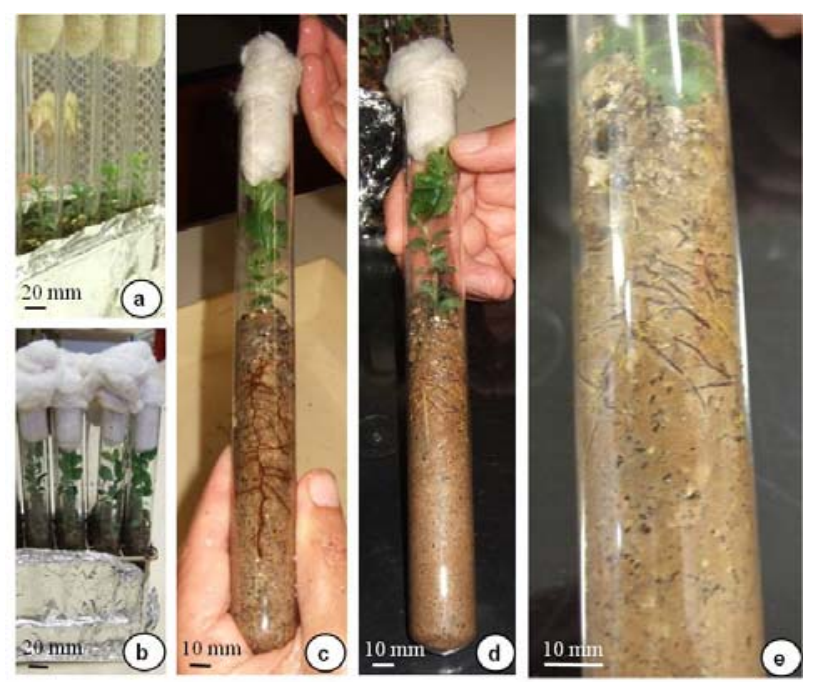

Fig. 1 Mycorrhizal synthesis: a - shoots immediately after transfer from the root expression medium to the synthesis tubes containing the inoculated substrate; $\mathbf{b}$ to $\mathbf{e}$ - different aspects of in vitro plantlet development after 5 months of culture in the substrate (b), showing a well developed root system (c and d) as well as an extensive root and substrate colonization by the $P$. arhizus mycelium, without any evidence of plant stress (c to e).

One month after the beginning of the experiments, roots were examined for mycorrhizal formation and the analyses showed that $P$. arhizus mycorrhizae had already developed, forming a pale yellow to yellow-brown mantle (Figs. 2a-b). The mycorrhizae had a typical cruciform appearance (Fig. $2 a$ ) and the mantle consisted of loosely interwoven hyphae (Figs. 2a-b). Histological studies performed in the mycorrhized roots showed that strawberry tree roots possess two vascular bundles of xylem and phloem (diarch roots) surrounded by 3-5 layers of cortical cells (Fig. 2c). Cross sections through these roots showed a typical arbutoid organization with a mantle, the Hartig net, and intracellular hyphal complexes which were confined to the epidermis (Figs. $2 c-f$ ).

Nine months after acclimatization, plants growing in the nursery were removed from the containers and the root system examined for the presence of arbutoid mycorrhizae and compared to control plants (not inoculated in vitro). All plants (previously in 
vitro inoculated or not) showed arbutoid mycorrhizae formation. When the substrate was previously in vitro inoculated with $P$. arhizus the results showed that mycorrhizae had developed, forming a pale yellow to yellow-brown mantle (Fig. 3a). Other features observed were a cruciform appearance and a compound structure, like a repeated branching (Figs. 3a-b). Analyses of fresh root sections made with a freezing microtome indicated the presence of a mantle, which consisted mainly of loosely interwoven hyphae (Fig. 3c) and also of the intracellular hyphal complexes confined to the epidermis (Fig. 3d), the Hartig net (Fig. $3 e$ ), and clamp-connections and cystidium (Fig. 3f). However, from what can be seen in Fig. 3 it is not clear whether the mycorrhizae formed by $P$. arhizus are still present as they are morphologically different from those in Fig. 2.
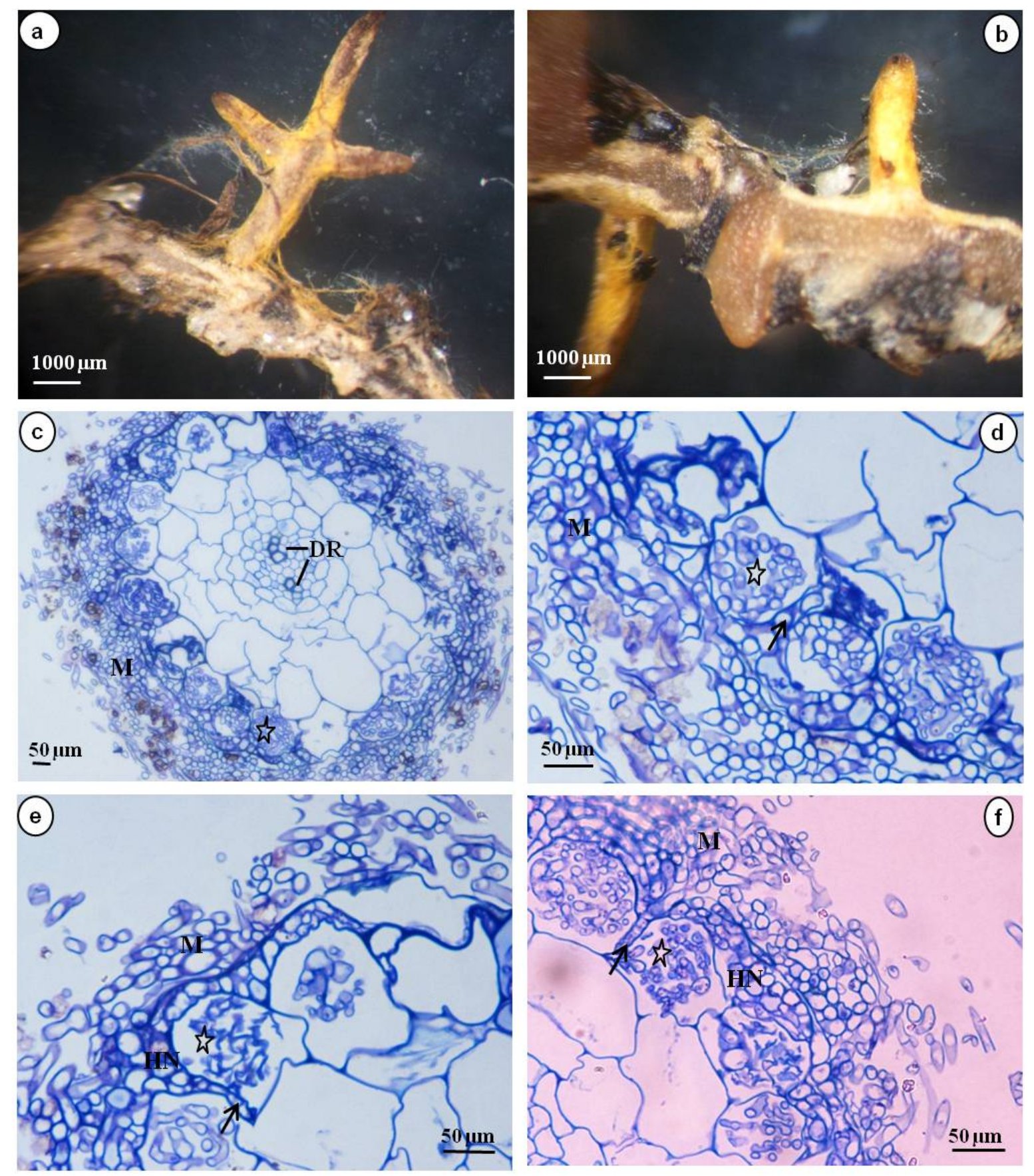

Fig. 2 Arbutoid mycorrhizae observations, after one month, in the synthesis tubes inoculated with $P$. arhizus: a - roots showing a cruciform appearance; $\mathbf{b}$ - detail of the thick pale yellow to yellow-brown mantle covering the root surface; $\mathbf{c}$ - cross section of a mycorrhized root showing the diarch root (DR) pattern of vascular bundle organization, the mantle (M) and intracellular hyphal complexes (star), which were confined to the epidermis; $\mathbf{d}$ to $\mathbf{f}$ - details of the cross sections showing the mantle (M), the Hartig net (HN), the paraepidermal Hartig net hyphae (arrows) and sectioned intracellular hyphal complexes (stars) within epidermal cells. 

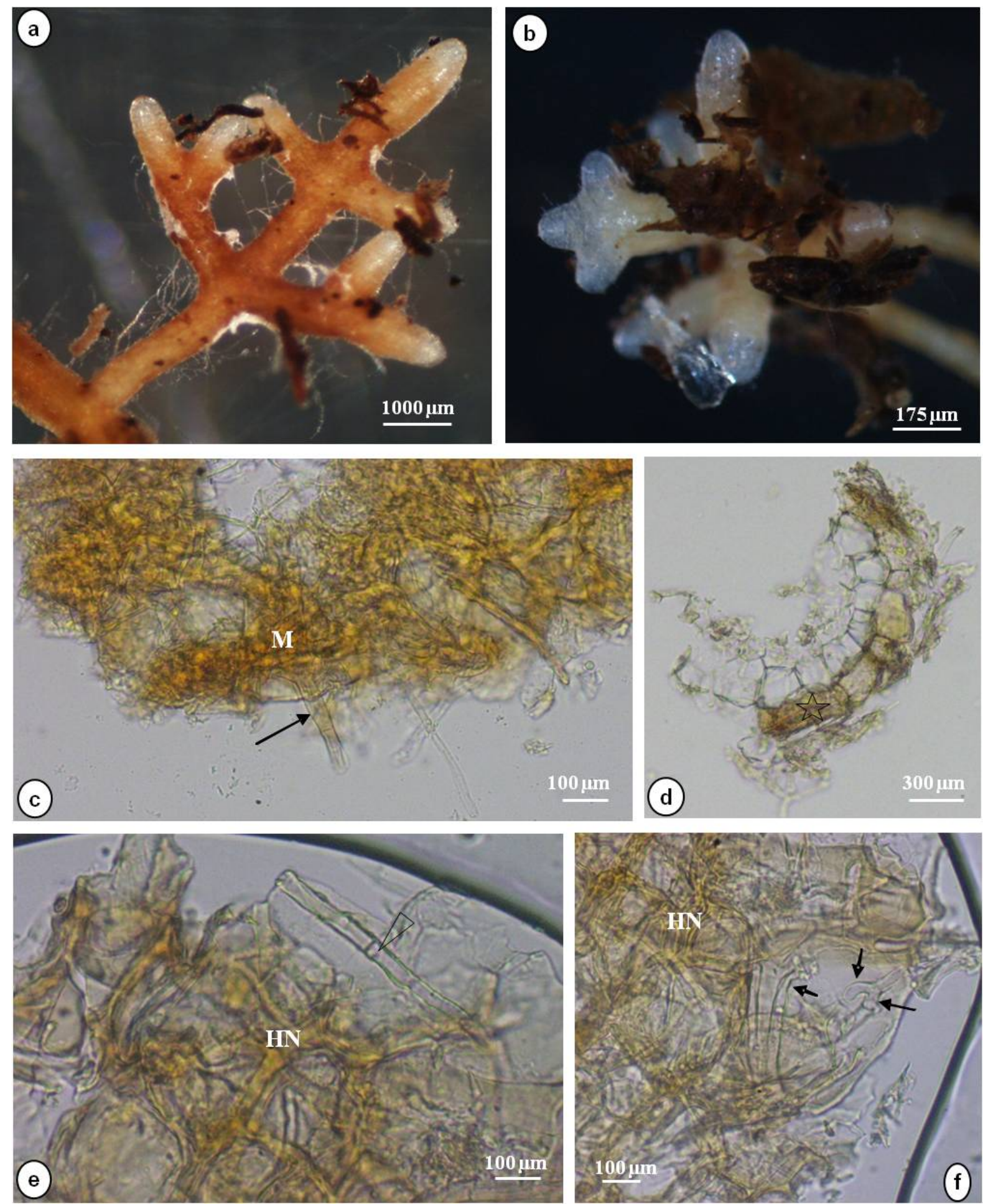

Fig. 3 Arbutoid mycorrhizae observations, nine months after acclimatization of previously mycorrhizal synthesis in vitro: a - mycorrhized roots showing a cruciform morphology; $\mathbf{b}$ - mycorrhizae showing a branched architecture; $\mathbf{c}$ - tissue cut with a freezing microtome showing the mantle (M) displaying loosely interwoven hyphae with a few emanating hyphae (arrow); $\mathbf{d}$ - intracellular hyphal complexes (star) in epidermal cells; $\mathbf{e}$ - aspect of the Hartig net (HN) and of a clamp-connection (arrow head); $\mathbf{f}$ - another aspect of the Hartig net (HN) showing a cystidium (arrow) and clamps (two arrows).

Nine months after acclimatization, control plants in nursery growing on a substrate which was not previously in vitro inoculated showed mycorrhizae development when roots were exam-

Springer ined under a stereomicroscope (Fig. 4). Mycorrhizae of various morphologies were found (Figs. $4 a-e$ ), some showing a typical cruciform appearance (Fig. 4a), others with a dichotomous 
branching (Fig. 4b), still others whitish in color (Figs. $4 c-d$ ) and pinnate edges branching morphology (Fig. 4f). displaying a coralloid type of branching (Fig. 4e), or showing
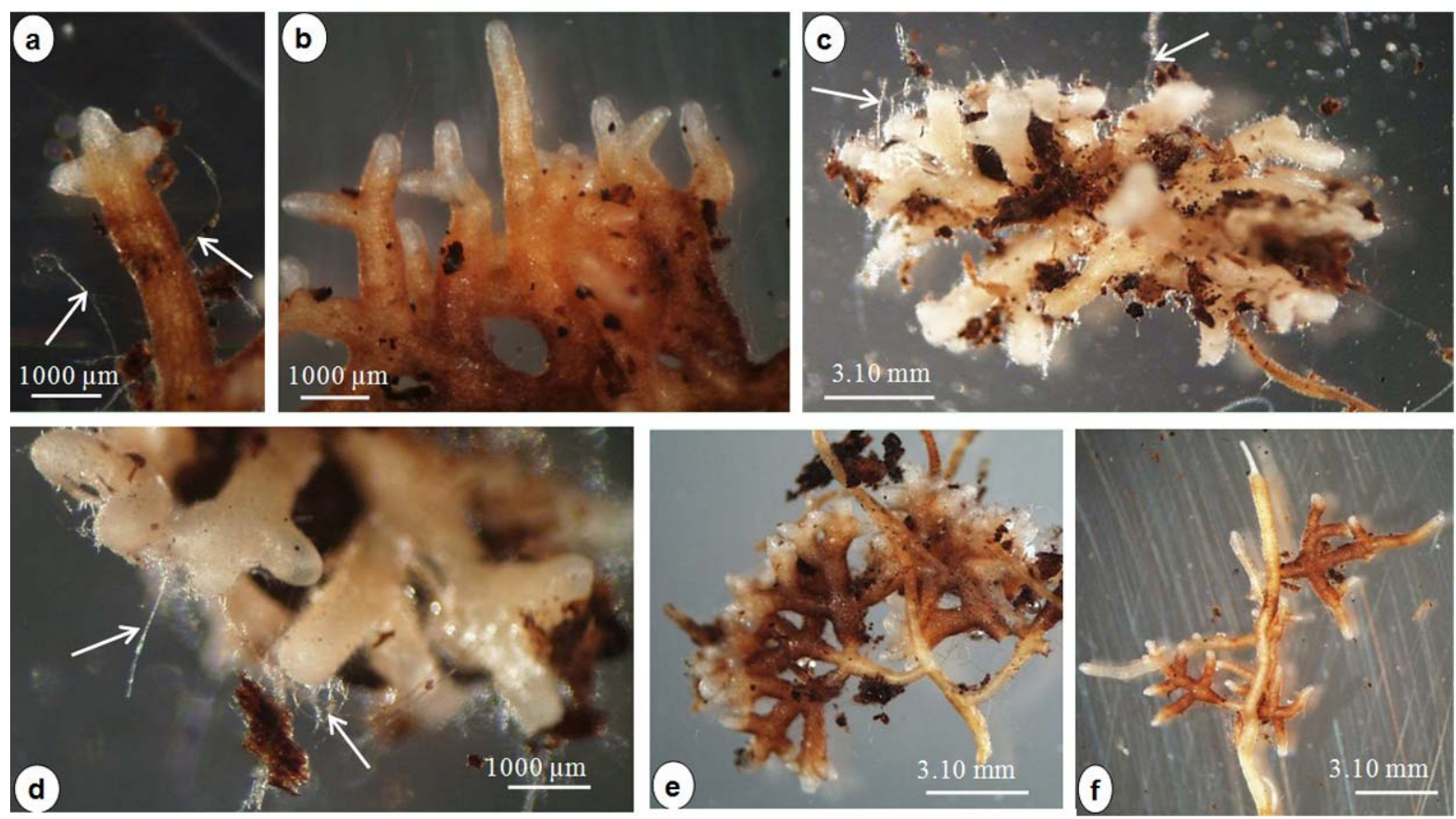

Fig. 4 Mycorrhizae observations on control plants growing in the nursery for nine months after acclimatization: a - mycorrhiza with a typical cruciform appearance (note the emanating hyphae; arrows); b - dichotomous mycorrhizae; c - mycorrhizae with compound structures (arrows); $d$ - mycorrhizae with white hyphae (arrows); e - mycorrhizae showing the coralloid branching morphology; $\mathrm{f}$ - mycorrhizae showing a pinnate edges branching morphology.

Twelve months after acclimatization, 10 plants growing in the nursery (previously in vitro inoculated) were examined, in order to identify the distinct mycorrhizal types, through molecular techniques. The results showed the presence of arbutoid mycorrhizae. However, these showed to be not from P. arhizus, but from two other basidiomycetes, namely Thelephora and Hebeloma, from the Telephoraceae and Cortinariaceae families, respectively (Table 1).

Table 1. Closest matches between nucleotide sequences and sequences from the GeneBank data base obtained using the BLAST search tool.

\begin{tabular}{lccl}
\hline $\begin{array}{l}\text { GeneBank's Acces- } \\
\text { sion number }\end{array}$ & E-value & $\begin{array}{c}\text { Similarity } \\
\%\end{array}$ & Closest species \\
\hline GU998124.1 & 0.0 & $99 \%$ & Thelephora $\mathrm{sp}$. \\
AY945290.1 & 0.0 & $90 \%$ & Thelephora $\mathrm{sp}$. \\
AB211272.1 & 0.0 & $97 \%$ & Hebeloma $\mathrm{sp}$. \\
HQ211740.1 & $7 \mathrm{e}-79$ & $94 \%$ & Hebeloma $\mathrm{sp}$. \\
\hline
\end{tabular}

Inoculation in nursery and field trial establishment

Plant height increment $(\mathrm{cm})$ was evaluated after two and four months of $P$. arhizus inoculation. After two months, no significant differences were found between treatments (C1M; C1S) and control plants (C1C). However, two months later, the best results
$(\mathrm{P}<0.05)$ were achieved when dry sporocarps mixed with water were tested (C1S; Table 2). On these conditions, the control plants showed the lowest value in height increment (Table 2).

Table 2. Effect of different inoculation treatments with $P$. arhizus on plants' height increment $(\Delta H)$ evaluated 2 and 4 months after inoculation under nursery conditions. Plants of the clone $\mathrm{C} 1$ were used.

\begin{tabular}{lcc}
\hline Treatments & $\Delta \mathrm{H} 2$ months $(\mathrm{cm})$ & $\Delta \mathrm{H} 4$ months $(\mathrm{cm})$ \\
\hline C1 C - Control plants & $10.7 \pm 0.4^{\mathrm{a}}$ & $14.4 \pm 0.7^{\mathrm{b}}$ \\
C1 M - Mycelium & $11.0 \pm 0.4^{\mathrm{a}}$ & $16.0 \pm 0.6^{\mathrm{b}}$ \\
C1 S - Sporocarps mixed & $10.8 \pm 0.3^{\mathrm{a}}$ & $19.1 \pm 0.7^{\mathrm{a}}$ \\
in water & & \\
\hline
\end{tabular}

In each column values (mean $\pm \mathrm{SE}$ ) followed by different letters are significantly different $(p \leq 0.01)$.

The survival rate found 12 months after field trial establishment was about $96.8 \%$, without significant differences. Twenty months after field trial establishment, height or height increment did not show significant differences due to the treatments tested (Table 3).

Twenty months after the field trial establishment, it was observed that roots of the plants which had been inoculated in nursery (C1M and $\mathrm{C} 1 \mathrm{~S}$ ) showed mycorrhyzed roots (Figs. 5a-g). Mycorrhization with Cenococcum geophilum (Figs. 5a-c), mycorrhizae displaying a compound structure (Fig. 5d) or my- 
corrhizae possessing a yellow-brown mantle (Fig. 5e) were other types observed. Cenococcum geophilum mycorrhizae were black (Figs. $5 a-c$ ), short and occasionally produced one or two short branches (Fig. $5 b$ ) but they were usually single (Fig. $5 c$ ). Observations performed in material sectioned with a freezing microtome showed a mantle with emanating hyphae with irregularly formed clamp-connections (Fig. 5f). Mycorrhizae with a typical cruciform appearance were also observed (Fig. $5 g$ ). However, some roots were also found in which mycorrhization could not be detected (Fig. 5h). Young roots without the presence of mycorrhizae (Fig. $5 h$ ) were characterized by the presence of root hairs morphologically different from the hyphae (Figs. 5b-d) and that could be easily distinguished.
Table 3. Effect of the different treatments on plants height and height increment $(\Delta \mathrm{H})$ evaluated 20 months after field trial establishment.

\begin{tabular}{lcc}
\hline Mycorrhizal treatments and genotype & $\mathrm{H}_{20 \text { months }}$ & $\Delta \mathrm{H}_{\left(\mathrm{H}_{20}-\mathrm{H}_{0}\right)}$ \\
\hline SE - seedlings & $68.6 \pm 5.3^{\mathrm{a}}$ & $57.7 \pm 4.8^{\mathrm{a}}$ \\
C1 C - Control plants & $76.2 \pm 6.7^{\mathrm{a}}$ & $54.8 \pm 6.9^{\mathrm{a}}$ \\
C1 M - Mycelium & $83.0 \pm 4.7^{\mathrm{a}}$ & $62.0 \pm 4.6^{\mathrm{a}}$ \\
C1 S - Sporocarps mixed in water & $84.7 \pm 5.1^{\mathrm{a}}$ & $60.8 \pm 5.0^{\mathrm{a}}$ \\
\hline
\end{tabular}

In each column values (mean $\pm \mathrm{SE}$ ) followed by same letters are not significantly different.
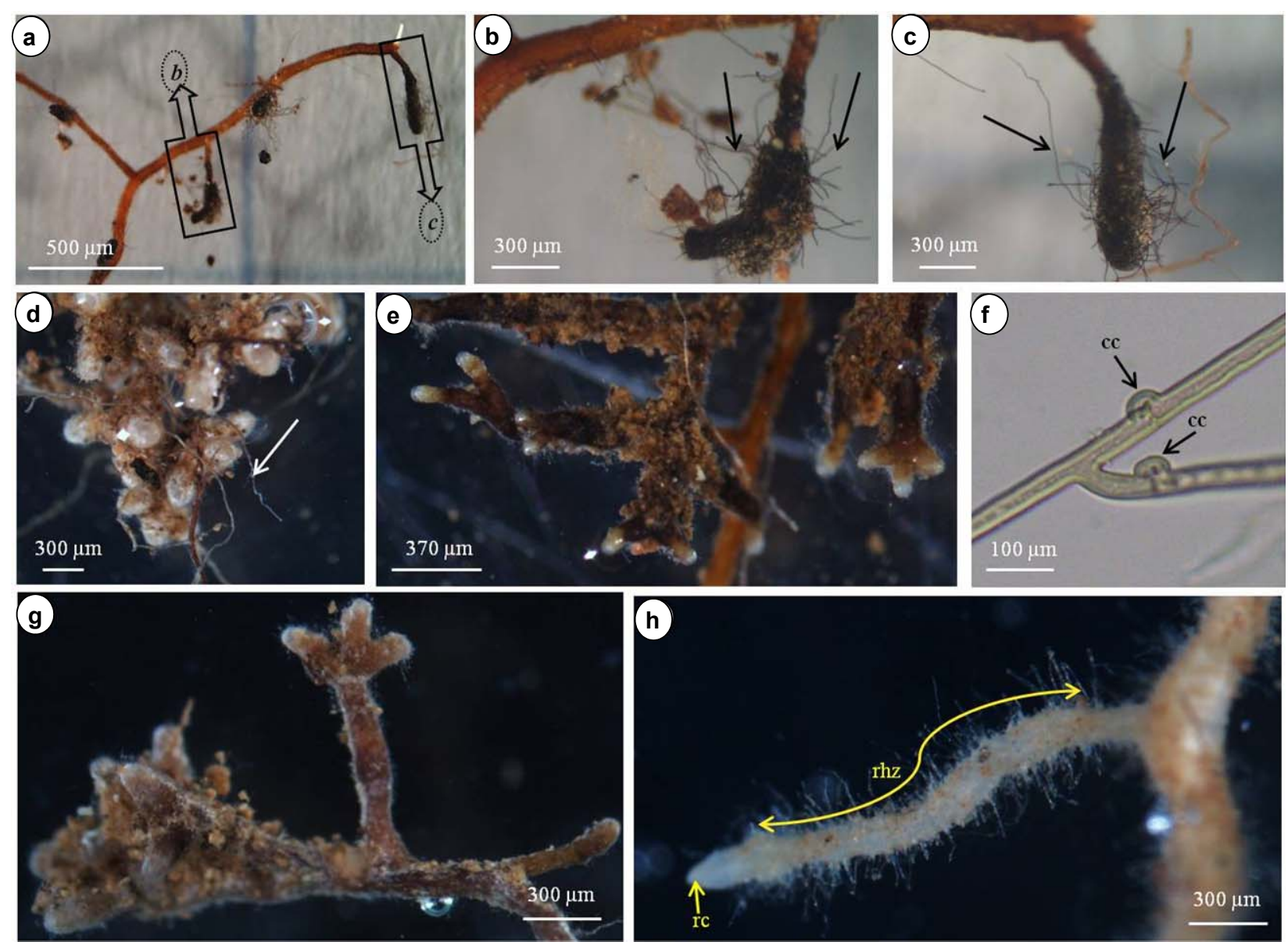

Fig. 5 Root observations 20 months after field trial establishment: a to $\mathbf{g}$ - mycorrhized roots; a to c - C. geophilum mycorrhizae, a - short mycorrhizae with a black mantle; figures details showing a mycorrhiza with two short branches (b) or single branch (c) with a compact black mantle and black hyphae growing from the mantle surface (arrows, $\mathbf{b}$ and $\mathbf{c}$ ); $\mathbf{d}$ - mycorrhiza presenting a compound structure, note the hyphae growing from the mantle (arrow); e - mycorrhizae showing a yellow-brown mantle; f - mantle hyphae possessing clamp-connections (cc); $\mathbf{g}$ - mycorrhizae showing a branched architecture and $\mathbf{h}$ - a young root without mycorrhizae showing the root hair zone (rhz) and the root cap (rc).

\section{Discussion}

Mycorrhizal synthesis in vitro

Our experiments showed that after five months on the synthesis tubes, during the acclimatization process of $A$. unedo plants, extensive substrate colonization by $P$. arhizus mycelium occurred. The treated plants showed a well-developed and branched root system with the presence of secondary roots. Overall, a thick yellow-brown mantle could be seen with the naked eye. Giovannetti et al. (1989) were able to identify two main types of mycorrhizae in A. unedo growing in natural conditions. The first was characterized by a thick black mantle

\section{Springer}


attributed to Cenococcum graniforme. The second was characterized by a thick mantle of closely interwoven hyphae. Histological studies demonstrated that epidermal cells were completely filled with the mycorrhizal fungi. Our data demonstrated that both plants cultured for one month in test tubes and those acclimatized for nine months showed mycorrhizae with a typical arbutoid organization, namely a thick mantle, the Hartig net, intracellular hyphal complexes confined to the epidermis and no evidence of VA formation. Similar observations were made by Münzenberger et al. (1992) on arbutoid mycorrhizae of A. unedo due to Laccaria amethystea in which a well developed mantle, the Hartig net, and a intracellular hyphal complex confined to the epidermis were also present.

These characteristics are quite different from those observed by Fusconi and Bonfante-Fasolo (1984) in the mycorrhizae of $A$. unedo growing in natural conditions and due to ascomycetous fungi. In this case, only a few hyphae occurred and a true mantle could not be found. Concerning the hyphal mantle in arbutoid mycorrhizae development, different observations have been reported. Thus, in Pyrola sp. Mycorrhizae, also classified as arbutoid, such as those of Arbutus and Arctostaphylos, the mature mycorrhizae are characterized by the presence of numerous intracellular hyphae, Hartig net, the absence of sheath, and the lack of fungal penetration into the cortex (Robertson and Robertson 1985).

According to Massicotte et al. (1993), in A. menziesii, the outer row of cortical cells develop a hypodermis showing suberin lamellae in their walls and a Casparian strip in radial walls, therefore confining the development of the Hartig net to the epidermis. The same authors also reported the presence of a variable fungal sheath (Massicotte et al. 1993). The presence of thick yellowbrown mantle was clearly observed in our studies, and the mycorrhizae displayed a typical cruciform appearance and a compound structure, like repeated branching. Similar features were reported by Molina and Trappe (1982), Massicotte et al. (1993) and Smith and Read (1997) on arbutoid mycorrhizae between $A$. menziesii and the basidiomycetes $P$. arhizus and Piloderma bicolor, respectively. According to Smith and Read (1997) this pattern of branching appears to arise from precocious initiation of individual lateral roots, rather than by dichotomy of the root apical meristem as typically seen in ectomycorrhizae of Pinus. Molina and Trappe (1982) sustain that in older associations, the cruciform structure usually branches forming pinnate fans or clusters, in which the tips of the compound mycorrhizae also have a cruciform appearance.

Our results showed the presence of root branching and secondary roots during the acclimatization process of in vitro inoculated plants. Similar results were also reported on ectomycorrhizal fungi of Castanea sativa micropropagated plants and seedlings (Martins 2004; Martins et al. 1996) and during vegetative propagation of conifers in which mycorrhization enhanced root formation as well as root branching of in vivo cuttings and in vitro adventitious shoots (Niemi et al. 2004).

Mycorrhizae formation may explain the survival rate (100\%) observed in our assays. The positive role of mycorrhization on plant development following micropropagation has been reported by a number of researchers. Thus, in Vaccinium angustifolium, also an Ericaceae, mycorrhization was used to improve plant acclimatization (Ratnaparkhe 2007). Other tree species in which mycorrhization helped to achieve higher levels of plant acclimatization were Castanea sativa (Martins 2010), Corylus avellana (Mirabelli et al. 2009), Juglans regia (Rai 2001), Leucaena leucocephala (Puthur et al. 1998), Olea europea (Cantos et al. 2009), Pinus pinaster and P. sylvestris (Parladé et al. 2004), Pinus pinea (Oliveira et al. 2003), Rhododendron (Eccher and Martinelli 2010), Sesbania sesban (Subhan et al. 1998), Vaccininium corymbosum (Eccher and Noé 2002) and Vitis vinifera (Cantos et al. 2009).

Nine months after acclimatization, the morphological studies showed that it was not clear whether the mycorrhizae formed by $P$. arhizus were still present as they were morphologically different from those previously observed in vitro 1 month after inoculation.

Twelve months after acclimatization, the sequencing of the PCR products amplified with ITS1F and ITS4 primers showed the presence of arbutoid mycorrhizae fungi of Thelephora sp. and Hebeloma sp. According to Ingleby et al. (1990), Hebeloma mycorrhizae are frequently associated with young trees of different species, and may be considered "early stage" fungi. Hebeloma are particularly common in tree nurseries and greenhouse potting composts, and in these conditions, tend to dominate root systems by impairing colonization by other species of fungi. Thelephora mycorrhizae are particularly abundant on seedlings growing in greenhouses or in nurseries. These kind of mycorrhizae are unspecific, are common in a wide range of habitats, and are also considered "early stage" fungi (Garbaye 1990; Ingleby et al. 1990). In addition, Thelephora is usually dominant, as fruitbodies are abundant and perennial, spreading spores throughout the year and well adapted to severe temperatures (Garbaye 1990). These features may help to explain our results observed 12 months after acclimatization of strawberry tree plants. Results obtained by Parladé et al. (2004) in $P$. pinaster and $P$. sylvestris are in line with these data. In fact, it was found that one-year old plants growing in the nursery showed levels of colonization with $L$. deliciosus highly reduced (50\% and $2 \%$ for $P$. pinaster and $P$. sylvestris respectively). Fungal persistence is a common problem following mycorrhization and has been often reported (Águeda et al. 2008; Parladé et al. 2004; Parladé et al. 2009; Rincón et al. 2005).

Inoculation with $P$. arhizus in nursery

In vitro plants acclimatized in the nursery were watered with either P. arhizus mycelium (vegetative inocula) or dry sporocarps and compared with the control. Different kinds of vegetative inocula production can be used for greenhouse or nursery inoculations, such as (1) spore inocula (Navarro et al. 2009), (2) mycelial suspensions on liquid medium, (3) mycelial slurries injected in the rhizosphere, (4) alginate-entrapped inoculums, and (5) inoculum production in a peat-vermiculite substrate (Parladé et al. 2004; Rincón et al. 2001). Parladé et al. (2004) reported that the percentage of colonized plants and the degree of 
colonization observed are dependent on the inoculation method and the plant-fungal strain interaction. In our assays two methods were tested: the vegetative inocula with the same strain that was tested in vitro and spore inocula.

According to Quinteiro (2005) one of the most interesting practical applications of induced mycorrhization is directly related to the increasing growth capacity of the host plants. Improved water and mineral nutrient uptake and a better tolerance to water deficit were reported with $A$. unedo plants inoculated in nursery, during hardening process, and later during transplanting and establishment period (Navarro et al. 2011; Navarro et al. 2009). However, the positive effect of mycorrhization on plant growth seems not to be a general rule. Thus, Gautry et al. (1991) did not find any increase in growth of seven clones of Pseudotsuga rooted cuttings inoculated with L. laccata and Hebeloma crustuliniforme. Rincon et al. (2001) tested seven ectomycorrhizal fungi (vegetative or spore inocula) with $P$. pinea seedlings (Hebeloma crustuliniforme, Laccaria laccata, P. arhizus, Melanogaster ambiguus, Rhizopogon luteolus, Rhizopogon roseolus and Scleroderma verrucosum) and were also unable to detect any increase in seedling growth.

These contradictory results may be ascribed to differences in the physiological conditions of the plant material and/or to the different species of fungi used. After four months, only plants from the dry sporocarp inoculation treatment showed higher growth rates than the control plants. Similar results were obtained by Chen et al. (2006) in E. urophylla inoculated in the nursery with spores of the ectomycorrhizal fungi Scleroderma sp.

The substrate used in the containers may also influence the mycorrhization success. Our assays were carried out in a mix of peat and perlite $(7: 3, \mathrm{v} / \mathrm{v})$. Perlite helps to maintain a high degree of porosity, thus enhancing substrate aeration, a situation that can facilitate mycorrhizae synthesis and further growth of the fungi (Gautry et al. 1991). Substrates usually used in nurseries, such as composted pine bark and soil mixtures have been associated to the appearance of aggressive and highly competitive pioneer mycorrhizae, a situation that can impair further colonization by more interesting and less competitive fungi species (Chen et al. 2006; Rincón et al. 2005).

In our assays, the use of composted pine bark was avoided. However, this is the substrate (mixed with peat) used for plant production (seedlings or cuttings) in the nursery for economic reasons and may contribute to natural mycorrhization. In other species, other types of substrates have been successfully used such as potting mix (vermiculite, peat and sand) in $P$. pinea (Rincón et al. 2005) and E. urophylla (Chen et al. 2006). However, further detailed studies must be conducted to evaluate, in a more precise way, the interaction between substrate and mycorrhizae establishment.

According to Rincon et al. (2001), spore inoculum of P. arhi$z u s$ has been successfully used in several experiments with different Pinus species and also with Quercus suber and Q. rubra. According to Quinteiro (2005) mycorrhization may help to reduce application of fertilizers by increasing nutrient uptake. This seems to occur in A. unedo, since increased height was higher in mycorrhized plants when dry sporocarps were tested, compared to those in which a fertilizer was added to the substrate. In large nurseries, this may reduce costs and contribute to a cleaner environment through the use of friendly agricultural practices.

Field trial observations

Following nursery treatments, a field trial was established with four types of plant material: inoculated clonal plants (vegetative inocula and dry sporocarps), control plants (not inoculated) and seedlings propagated in the nursery. Several authors concur that is advisable to reduce the use of fertilizers, to stimulate establishment of the symbiotic association (Águeda et al. 2008; Fortin et al. 2008; Rincón et al. 2005). Only seedlings were fertilized when planted in the field, the normal procedure in plantation. Results, reported one year later, showed a survival rate of $96.8 \%$, without significant differences between treatments. Twenty months later, plant height and height increment were higher (with no significant differences) in both treatments with inoculated plants (vegetative inocula and dry sporocarps) than in control plants and seedlings. Kosola et al. (2007) reported that mycorrhization of Vaccinium macrocarpon with Rhizoscyphus ericae promotes field establishment, stress tolerance and growth, making it a useful approach for the management of crop plants. In our experiment, no significant differences were found between all treatments. A common agricultural practice in field plantations is the use of a slow release fertilizer. However, as mentioned above, mycorrhization seems to be a more interesting option because it is cheaper, cleaner, and improves the physiological conditions of the plants.

Root analysis indicated that plants of strawberry tree were mycorrhized with different fungi, one of them being Cenococcum geophilum. According to Ingleby et al. (1990) this fungal species is widespread and easy to identify by its black color with characteristic emanating hyphae (thick, straight and invariably broken because of their fragile nature) and mantle surface (compact and uneven) features. This type of mycorrhizae with emanating hyphae was also observed in $A$. unedo roots. According to Ingleby et al. (1990) the emanating hyphae are absent, only when C. geophilum mycorrhizae get older. Similar conclusions were forwarded by Richard et al. (2005) who have demonstrated, through molecular analysis, that in $A$. unedo plants growing in an old Mediterrean forest dominated by Quercus ilex, C. geophilum was the dominant species among 30 sampled plants. The same authors were only able to identify three other species besides $C$. geophilum, namely two Thelephoraceae species and Inocybe tigrina.

Twenty months after the field trial was established, the $A$. unedo roots did not show any presence of the $P$. arhizus previously inoculated under nursery conditions. These results suggest that $A$. unedo plants had established mycorrhizae with other natural species of mycorrhizal fungi. This fact may explain why plant growth did not show differences between treatments, 20 months after field trial establishment. Fungal persistence is other problem reported by several authors (Águeda et al. 2008; Parladé et al. 2004; Parladé et al. 2009; Rincón et al. 2005). In our experiments, the use of a non-specific strain of $P$. arhizus might 
explain its absence in the roots 20 months after field trial establishment, likely due to the lower competitiveness of the strain used when compared to other mycorrhizal fungi. It is critical to know the threshold colonization level required to ensure fungal persistence, as well as screening fungal strains for their aggressiveness under nursery and field conditions, which is a prerequisite for the successful commercial application of inoculation techniques (Parladé et al. 2004).

Further assays on the mycorrhization of $A$. unedo plants will be focused on the selection of more competitive fungal strains and on the threshold fungal colonization level required to increase the frequency of mycorrhization and to assure mycorrhization persistence during further plant growth.

\section{Acknowledgments}

We thank Vera Santos, Iker Sorzabalbere, Mafalda Simões and José Maia, who helped us in the laboratory, in the nursery and field work. F. Gomes was supported by a $\mathrm{PhD}$ fellowship (SFRH/BD/37170/2007) from the Portuguese Foundation for Science and Technology (FCT).

\section{References}

Agerer R, Rambold G. 2004-2010. DEEMY - An information system for characterization and determination of ectomycorrhizae. München, Germany. Available at: www.deemy.de Nov./2009.

Águeda B, Parladé JF, Fernández-Toirán LM, Cisneros O, Miguel AM, Modrego MP, Martínez-Pena F, Pera J. 2008. Mycorrhizal synthesis between Boletus edulis species complex and rockroses (Cistus sp.). Mycorrhiza, 18: 443-449.

Altschul SF, Madden TL, Schaffer AA, Zhang J, Zhang Z, Miller W, Lipman DJ. 1997. Gapped BLAST and PSI-BLAST: a new generation of protein database search programs. Nucleic Acids Research, 25: 3389-3402.

Anderson WC. 1984. A revised tissue culture medium for shoot multiplication of Rhododendron. Journal of the American Society for Horticultural Science, 109: 343-347.

Cantos M, Liñán J, Carretero CL, Troncoso A, Azcón R. 2009. Influence of mycorrhization during the hardening process of micropropagated plants. Acta Horticulturae, 812: 455-460.

Chen YL, Kang LH, Dell B. 2006. Inoculation of Eucalyptus urophylla with spores of Scleroderma in a nursery in south China: Comparison of field soil and potting mix. Forest Ecology and Management, 222: 439-449.

De Fossard RA, Nitsch C, Cresswell RJ, Lee HCM. 1974. Tissue and organ culture of Eucalyptus. New Zealand Journal of Forest Science, 4: 267-278.

Duncan DB. 1955. Multiple range and multiple F tests. Biometry, 11: 1-42.

Eccher T, Martinelli M. 2010 Inoculation of Rhododendron cultivars in vitro with different strains of ericoid endomycorrhizae. Acta Horticulturae, 865: 327-332.

Eccher T, Noé N. 2002. Influence of Ericoid endomycorrhizae inoculated in vitro on rooting and early growth of micropropagated plants of Vaccinium corymbosum L. Acta Horticulturae, 574: 373-378.

Fortin JA, Plenchette C, Piché Y. 2008. Les mycorhizes la nouvelle révolution verte. Ed. Multimondes, Ed. Quae, Québec.

Fusconi A, Bonfante-Fasolo P. 1984. Ultrastructural aspects of host endophyte relationships in Arbutus unedo L. mycorrhizas. New Phytologist, 96:
$397-410$.

Garbaye J. 1990. Pourquoi et comment observer l'état mycorhizien des plants forestiers. Rev. Revue Forestière Française, Biologie et Forêt, XLII 1: $35-47$.

Gardes M, Bruns TD. 1993. ITS primers with enhanced specificity for basidiomycetes : application to the identification of mycorrhizae and rusts. Molecular Ecology, 2: 113-118.

Gautheret RJ. 1959. La culture des tissues végétaux, techniques et réalisations. Masson \& Cie, Paris.

Gautry JY, Jouvenceau S, Thivolle-Cazat A. 1991 Mycorrhization artificielle du Douglas et de l'épicéa et interaction clone x champignon. Annais AFOCEL, 125-158.

Giovannetti M, Lioi L, Picci G. 1989 Host and non-host relationships between Arbutus unedo L. and mycorrhizal fungi. Agriculture, Ecosystems \& Environment, 29: 169-172.

Gobert A, Plassard C. 2008. The beneficial effect of mycorrhizae on N utilization by host-plant: myth or reality? In: Varma A. (ed.), Mycorrhiza Genetics and Molecular Biology, Eco-function, Biotechnology, Eco-physiology, Structure and Systematic. $3^{\text {rd }}$ ed. Berlin: Springer, pp. 209-240

Gomes F, Canhoto JM. 2009. Micropropagation of strawberry tree (Arbutus unedo L.) from adult plants. In Vitro Cellular \& Developmental Biology Plant, 45: 72-82.

Gomes F, Lopes ML, Santos T, Canhoto JM. 2009 Micropropagation of selected trees of Arbutus unedo L. trough axillary shoot proliferation and somatic embryogenesis. Acta Horticulturae, 839: 111-116.

Gomes F, Simões M, Lopes ML, Canhoto JM. 2010 Effect of plant growth regulators and genotype on the micropropagation of adult trees of Arbutus unedo L. (strawberry tree). New Biotechnology, 27: 882-892.

Harrison MJ. 1999. Molecular and cellular aspects of the arbuscular mycorrhizal symbiosis. Annual Review of Plant Physiology and Plant Molecular Biology, 50: 361-389.

Ingleby K, Mason PA, Last FT, Fleming V. 1990. Identification of ectomycorrhizas, ITE Research Publication $n^{\circ}$ 5. NE Research Council, HMSO Publ., London.

Jacob C, Courbot M, Brun A, Steinman HM, Jacquot JP, Botton B, Chalot M. 2001. Molecular cloning, characterization and regulation by cadmium of a superoxide dismutase from the ectomycorrhizal fungus Paxillus involutus. European Journal of Biochemistry, 268: 3223-3232.

Kosola KR, Workmaster BAA, Spada PA. 2007. Inoculation of cranberry (Vaccinium macrocarpon) with the ericoid mycorrhizal fungus Rhizoscyphus ericae increases nitrate influx. New Phytologist, 176: 184-196.

Lopes ML, Gomes F, Canhoto JM. 2011. Somatic embryogenesis induction and plant conversion from young leaves of adult strawberry tree-derived shoots: role of the genotype. XXXVI Jornadas Portuguesas de Genética, Abst, 68.

Martins A. 2004. Micorrização controlada de Castanea sativa Mill.: Aspectos fisiológicos da micorrização in vitro e ex vitro. $\mathrm{PhD}$ Thesis. University of Lisbon.

Martins A. 2010. Mycorrhizal inoculation of Chestnut seedlings: effect on survival and growth after transplantation. Acta Horticulturae, 866: 325-334.

Martins A, Barroso J, Pais MS. 1996 Effect of ectomycorrhizal fungi on survival and growth of micropropagated plants and seedlings of Castanea sativa Mill. Mycorrhiza, 6: 265-270.

Massicotte HB, Melville LH, Molina R, Peterson RL. 1993. Structure and histochemistry of mycorrhizae synthesized between Arbutus menziesii (Ericaceae) and two basidiomycetes Pisolithus tinctorius (Pisolithaceae) and 
Piloderma bicolor (Corticiaceae). Mycorrhiza, 3: 1-11.

Mirabelli C, Tullio M, Pierandrei F, Rea E. 2009. Effect of arbuscular mycorrhizal fungi on micropropagated hazelnut (Corylus avellana L.) plants. Acta Horticulturae, 812: 467-472.

Molina R. 1979. Pure culture synthesis and host specificity of red alder mycorrhizae. Canadian Journal of Botany, 57: 1223-1228.

Molina R, Trappe JM. 1982 Lack of mycorrhizal specificity by the Ericaceous hosts Arbutus menziesii and Arctostaphylos uva-ursi. New Phytologist, 90: 495-509.

Münzenberger E, Kottke I, Oberwinkler F. 1992. Ultrastructural investigations of Arbutus unedo -Laccaria amethystea mycorrhiza synthesized in vitro. Trees, 7: 40-47.

Navarro A, Banón S, Morte A, Sánchez-Blanco MJ. 2011. Effects of nursery preconditioning through mycorrhizal inoculation and drought in Arbutus unedo L. plants. Mycorrhiza, 21: 53-64.

Navarro A, Sánchez-Blanco MJ, Morte A, Banón S. 2009. The influence of mycorrhizal inoculation and paclobutrazol on water and nutritional status of Arbutus unedo L. Environmental Experimental Botany, 66: 362-371.

Niemi K, Scagel C, Häggman H. 2004. Application of ectomycorrhizal fungi in vegetative propagation of conifers. Plant Cell, Tissue and Organ Culture, 78: 83-91.

Noé N, Eccher T, Borra M. 2002. The use of selected mycorrhizae for quality improvement of Highbush Blueberry (Vaccinium corymbosum L.) plant production. Acta Horticulturae, 574: 387-392.

Oliveira P, Barriga J, Cavaleiro C, Peixe A, Potes AZ. 2003. Sustained in vitro root development obtained in Pinus pinea L. inoculated with ectomycorrhizal fungi. Forestry, 76: 579-587.

Parladé J, Pera J, Luque J. 2004. Evaluation of mycelial inocula of edible Lactarius species for the production of Pinus pinaster and P. sylvestris mycorrhizal seedlings under greenhouse conditions. Mycorrhiza, 14: 171-176.

Parladé X, Pera J, De La Varga H, Hortal S. 2009. Tracking inoculated ectomycorrhizal fungi by Real-Time PCR. 25, Supplement 1, $14^{\text {th }}$ European Congress on Biotechnology, Abst S375.

Peterson RL, Massicotte HB. 2004. Exploring structural definitions of mycorrhizas, with emphasis on nutrient-exchange interfaces. Canadian Journal of Botany, 82: 1074-1088.
Piotto B, Piccini C, Arcadu P. 2001. La ripresa della vegetazione dopo gli incendi nella regione mediterranea. In: Piotto B, Noi A. (eds), Propagazione per seme di alberi e arbusti della flora mediterranea, Roma, pp. 32-38.

Puthur JT, Prasad KVSK, Sharmila P, Saradhi PP. 1998. Vesicular arbuscular mycorrhizal fungi improves establishment of micropropagated Leucaena leucocephala plantlets. Plant Cell, Tissue and Organ Culture, 53: 41-47.

Quinteiro SL. 2005. Respuesta de siete orígenes ibéricos de Pinus pinaster Aiton frente a la inoculación en vivero con Pisolithus tinctorius y Paxillus involutus. PhD Thesis. University of Santiago de Compostela.

Rai MK. 2001 Current advances in mycorrhization in micropropagation. In Vitro Cellular \& Developmental Biology - Plant, 37: 158-167.

Ratnaparkhe MB. 2007. Blueberry. In: Kole C. (ed) Genome mapping and molecular breeding in plants, Fruits and Nuts, Berlin: Springer, pp. 217-227.

Richard F, Millot S, Gardes M, Selosse MA. 2005. Diversity and specificity of ectomycorrhizal fungi retrieved from an old-growth Mediterranean forest dominated by Quercus ilex. New Phytologist, 166: 1011-1023.

Rincón A, Alvarez IF, Pera J. 2001. Inoculation of containerized Pinus pinea L. seedlings with seven ectomycorrhizal fungi. Mycorrhiza, 11: 265-271.

Rincón A, Parladé J, Pera J. 2005. Effects of ectomycorrhizal inoculation and the type of substrate on mycorrhization, growth and nutrition of containerized Pinus pinea L. seedlings produced in a commercial nursery. Annals of Forest Science, 62: 817-822.

Robertson DC, Robertson JA. 1985. Ultrastructural aspects of Pyrola mycorrhizae. Canadian Journal of Botany, 63: 1089-1098.

Smith SE, Read DJ. 1997. Arbutoid and monotropoid mycorrhizas. Mycorrhizal Symbiosis, $2^{\text {nd }}$ ed. San Diego: Academic Press, Harcourt Brace and Company Publishers.

Subhan S, Sharmila P, Saradhi PP. 1998 Glomus fasciculatum alleviates transplantation shock of micropropagated Sesbania sesban. Plant Cell Reports, 17: 268-272.

White TJ, Bruns TD, Lee S, Taylor JW. 1990. Amplification and direct sequencing of fungal ribossomal RNA genes for phylogenetics. In: Innis MA, Gelfand DH, Sninsky JJ, White TJ. (eds), PCR Protocols: a guide to methods and amplifications. London: Academic Press, pp. 315-322. 